2) Deficient of normal fall of blood pressure at night is associated with increased risk of cardiovascular disease (2). Reverse-dipper or riser patients generate a small portion of hypertensive patients (3). Although this group is at risk for stroke (commonly intracranial hemorrhage), especially in elderly patients (4). However, despite the evidences, reverse-dipping is not mentioned in the valid guide- lines currently (5). The small number of patients was another deficiency in our study to obtain wide-angle data. Consequently, we did not examine and create a reverse-dipper group. Studies involving more patients with longer follow-ups may contribute valuable parts of further guidelines.

\title{
Oğuz Akkuş
}

Department of Cardiology, Van Education and Research Hospital; Van-Turkey

\section{References}

1. Tosu AR, Demir S, Kaya Y, Selçuk M, Akdağ $S$, Işık T, et al. Association of $P$ wave dispersion and left ventricular diastolic dysfunction in non-dipper and dipper hypertensive patients. Anadolu Kardiyol Derg 2014; 14: 251-5. [CrossRef]

2. Ohkubo T, Imai Y, Tsuji I, Nagai K, Watanabe N, Minami N, et al. Relation between nocturnal decline in blood pressure and mortality. The Ohasama Study. Am J Hypertens 1997; 10: 1201-7. [CrossRef]

3. Salwa P, Gorczyca-Michta I, Kluk M, Dziubek K, Wozakowska-Kaplon B. Variability of circadian blood pressure profile during 24-hour ambulatory blood pressure monitoring in hypertensive patients. Kardiol Pol 2014; 5: 432-7. [CrossRef]

4. Kario K, Pickering TG, Matsuo T, Hoshide S, Schwartz JE, Shimada K. Stroke prognosis and abnormal nocturnal blood pressure falls in older hypertensives. Hypertension 2001; 4: 852-7. [CrossRef]

5. Taylor J. $2013 \mathrm{ESH} / \mathrm{ESC}$ guidelines for the management of arterial hypertension. Eur Heart J 2013; 28: 2108-9.

Address for Correspondence: Dr. Oğuz Akkuş,

Van Eğitim ve Araştırma Hastanesi, Kardiyoloji Kliniği, Van-Türkiye

Phone: +90 3264562142

E-mail: oakkusfb@gmail.com

Available Online Date: 25.12.2014

\section{Author`s Reply}

To the Editor,

We thank all of the authors for their valuable comments, and we were delighted to see your interest to our study (1), entitled "Association of $\mathrm{P}$-wave dispersion and left ventricular diastolic dysfunction in nondipper and dipper hypertensive patients," published in the April issue of The Anatolian Journal of Cardiology 2014; 14: 251-5.

1) You are right about the mentioned parameters, such as e', a', and E/e'; this may be a deficiency of our study. Nevertheless, we will take your advice into consideration for future research. 